\title{
EPIFANIA E PARALISIA: O PASSEIO FEMININO EM “A FUGA", DE CLARICE LISPECTOR
}

\author{
EPIPHANY AND PARALYSIS: THE FEMININE OUTING IN “A FUGA” (THE \\ ESCAPE), BY CLARICE LISPECTOR
}

José Vilian Mangueirai

RESUMO: A partir dos termos epifania e paralisia, apresentados pelo autor irlandês James Joyce, este texto procura analisar o conto "A fuga", da escritora Clarice Lispector, numa tentativa de entender o percurso da protagonista, as construções sociais oriundas do espaço em que a protagonista vive e, também, seus anseios e frustações.

PALAVRAS-CHAVE: Paralisia. Epifania. Conto moderno. Personagem feminina.

ABSTRACT: Taking into consideration the terms epiphany and paralysis, presented by the Irish author James Joyce, this text aims to analysis the short story "A fuga" ("The escape"), by the writer Clarice Lispector, as an attempt to understand the main character's journey, the social constructions created by the space in which she is living, and also the main character's desires and frustrations.

KEYWORDS: Paralysis. Epiphany. Modern short-story. Female character.

Submetido em: 16 out. 2018

Aprovado em: 29 nov. 2018

\section{Alumbramento}

Influenciada pelas técnicas de composição artística dos autores do Modernismo inglês, principalmente James Joyce, Virginia Woolf e Katherine Mansfield, a escritora Clarice Lispector deixa transparecer em sua obra o legado que estes autores lhe ofereceram.

Em uma entrevista concedida a Marina Colassanti e João Salgueiro, em 20 de outubro de 1976, Clarice Lispector reconhece o quanto a obra de Katherine Mansfield a marcou. Certo trecho da entrevista diz o seguinte: "Com o primeiro

\footnotetext{
i Doutor em Letras pela Universidade Federal da Paraíba. Professor da Universidade Estadual da Paraíba (UEPB), atuando na Graduação em Letras como Professor de Literatura AngloAmericana. E-mail: vilian_mangueira@yahoo.com.
} 
dinheiro que ganhei, entrei, muito altiva, numa livraria para comprar um livro. Aí mexi em todos, e nenhum me dizia nada. De repente eu disse: 'Ei, isso aí sou eu!'. Eu não sabia que Katherine Mansfield era famosa, descobri sozinha. Era o livro Felicidade" (apud ROSAS, 1999, p. 7).

A relação Clarice Lispector / Virginia Woolf pode ser percebida através da utilização de uma escrita não linear, do uso constante do fluxo de consciência, na discussão sobre o sujeito feminino que se insere no contexto familiar ou literário, e na técnica do monólogo interior, entre outros. Luciano Rodrigues Lima, ao comparar as histórias de alguns contos das duas autoras, chama atenção para o fato de as duas construírem um enredo "desolado, inacentuado, [...] composto não de uma trama, mas de um incidente que dispara o transe psicológico, subjetivo e estético". (LIMA, 2008, p. 41).

Os mesmos recursos de criação - fluxo de consciência e monólogo interior - também podem ser influências oriundas da escrita de James Joyce. Além desse ponto, podemos falar da utilização da epifania, criada por James Joyce, nas narrativas de Clarice Lispector. Dessa forma, é incontestável para o leitor atento dessa escritora brasileira a identificação do quanto estes autores do Modernismo inglês têm papel importante na criação de Lispector. Com base nesse argumento, interessa-nos investigar como o conto "A fuga" utiliza epifania e paralisia para estruturar a narrativa.

O escritor irlandês James Joyce, além de um legado de obras literárias representativas do Modernismo inglês e ocidental, também contribuiu com a criação de termos literários que influenciariam outros escritores que se inspiraram na produção desse autor. Do legado de James Joyce, dois termos ganharam destaque em suas narrativas: epifania e paralisia. Usados com propriedade em seu livro de contos, Dublinenses, esses dois termos servem para caracterizar as atitudes de grande parte dos protagonistas das narrativas do livro, que são pegos diante de momentos de reconhecimento da vida, e para compor o ambiente onde as narrativas acontecem, a capital da Irlanda, Dublin, imersa em uma representação de inércia.

Em diferentes partes de seus escritos, James Joyce pincelou definições para estes dois termos ou procurou explicar a utilização deles em suas narrativas. Segundo João Camillo Penna, o termo epifania aparece na obra de 
James Joyce "em uma versão intermediária não publicada de $O$ retrato do artista enquanto jovem, Stephen hero, escrita 1904 e 1906" (PENNA, 2010, p. 69). Nessa parte específica do livro, assim o escritor explica o que seria epifania:

\begin{abstract}
This triviality made him think of collecting many such moments together in a book of epiphanies. By an epiphany he meant a sudden spiritual manifestation, whether in the vulgarity of speech or of gesture or in a memorable phase of the mind itself. He believed that it was for the man of letters to record these epiphanies with extreme care, seeing that they themselves are the most delicate and evanescent of moments. (JOYCE, 1963, p. 211).
\end{abstract}

Os estudiosos Robert Scholes e Florence L. Walzl afirmam que Joyce criou o termo para significar uma apreensão intelectual ou espiritual que representaria uma iluminação ${ }^{1}$. (1967, p. 152). Assim, o termo deve ser entendido como o momento de iluminação em que ocorre uma percepção da essencialidade de um determinado período, de uma situação, de um objeto ou de uma pessoa. Em Dublinenses, alguns personagens vivenciam momentos epifânicos que Ihes possibilitam um impulso poderoso e que thes oferece uma chance de projeção de mudança de vida, como ocorre com a personagem título do conto "Eveline": ao ouvir o som de uma melancólica canção italiana, Eveline relembra o momento da morte de sua mãe e percebe que é necessário fugir da sua casa (o lar e a Irlanda) para ser feliz - "Levantou de súbito terror. Fugir! [...] Queria viver". (JOYCE, 2006, p. 40). Mas esses momentos de realização vão se chocar com outra característica dos personagens dessa obra: a paralisia.

Com relação ao termo paralisia, o escritor irlandês o aplica para definir o modo de vida da cidade de Dublin, representado no seu livro de contos Dublinenses. Em uma carta datada de 1905, para o editor do livro, o escritor assim explica o motivo da criação dessa coletânea de narrativas curtas: "My intention was to write a chapter of moral history of my country and I chose Dublin for the scene because that city seemed to me the centre of paralysis." (apud BROWN, 2000, p. xxxi). Essa mesma ideia vai ser identificada em $O$ retrato do artista enquanto jovem, Stephen hero, no momento em que o protagonista ouve uma conversa entre um jovem sedutor e uma jovem parada "em pé nos degraus

\footnotetext{
${ }^{1}$ No original: "Joyce himself set the pattern for the use of the term epiphany as a spiritual or intellectual apprehension which represented an enlightenment".
} 
do pórtico de uma dessas casas de tijolos marrons que parecem a própria encarnação da paralisia irlandesa". (JOYCE, 2012, p. 171). Levando em conta o que é apresentado nas narrativas de Dublinenses, que mostram diferentes personagens presos à lentidão das ações diárias e à falta de perspectiva de mudança de vida, personagens que ensaiam uma projeção de mudança, mas que acabam reconhecendo a total falta de possibilidade de melhoria para suas vidas, é possível afirmar que o termo paralisia se aplica à inabilidade que determinados personagens têm de mudar o curso de suas vidas e de reverterem a rotina que obstrui a realização de seus desejos interiores.

Renomados estudiosos da obra de Clarice Lispector, como Benedito Nunes e Affonso Romano de Sant'Anna, identificam na obra dessa escritora brasileira a recorrência da utilização de momentos epifânicos em diferentes narrativas - sejam elas romances ou contos. Assim, é quase um lugar comum afirmar que este e/ou aquele texto de Clarice Lispector possuem um personagem que passa por um momento de iluminação sobre si ou sobre a realidade que o circunda. O que ainda deixa a desejar é o aprofundamento da análise do significado desse momento de realização vivenciado por determinados personagens criados por essa escritora. Diante do exposto, este estudo procura entender a funcionalidade da epifania vivenciada pela protagonista do conto " $A$ fuga", assim como procura identificar as ações da personagem, levando em conta a caracterização de paralisia apontada por James Joyce para os personagens de Dublinenses.

\section{Andanças para o ponto de partida}

"A fuga", de 1979, faz parte do livro $A$ bela e a fera e narra a história de uma mulher que vaga pelas ruas, com medo e sem rumo, debaixo de uma grande chuva, evidenciando conflitos existenciais sofridos, mas até então desconhecidos para a personagem. Casada há doze anos, essa mulher experimenta três horas de liberdade, longe de casa, se sentindo restituída de suas forças. Ela sai para ver o mar e, em plena chuva, fica pensando como seria o fundo do mar, se realmente ele existe ou não. Essas reflexões conduzem a personagem pelas ruas, criando em sua alma uma grande angústia: 
Quis sentar-se num banco do jardim, porque na verdade não sentia a chuva e não se importava com o frio. Só mesmo um pouco de medo, porque ainda não resolvera o caminho a tomar. O banco seria um ponto de repouso. Mas os transeuntes olhavam-na com estranheza e ela prosseguia na marcha. (LISPECTOR, 1997, p. 23).

A partir desse desejo de seguir sem rumo, em busca de alguma liberdade perdida, a mulher anda pelas ruas e, em meio às suas divagações, lembra-se de um momento da escola primária que lhe traz sabor de liberdade. Coincidentemente, ela percebe que há doze anos, mesma quantidade de tempo que permanece casada, não sente essa liberdade, porque a simples presença do marido lhe tolhe todas as ações, quiçá os pensamentos. A chuva para; ela pensa em não voltar para casa, o que é infinitamente consolador. Pensa em ir para um hotel, em tomar um navio e viajar para longe. Tudo isso nos faz perceber que a angústia da personagem gira em torno de sua rotina de mulher casada. Assim, o que ela buscava era algo simples, era viver a vida sem amarras, sem ter que se justificar ou fazer o papel de esposa, de dona de casa.

Por um instante, se imagina saindo da vida oprimida, mas se dá conta de que não tem dinheiro, um marcador de sua dependência do marido. Mas ela segue, devaneando, imaginando como seria ser livre, como seria viver de verdade: "ela ria. Agora pode rir... eu comia caindo, vivia caindo. Vou procurar um lugar onde por os pés..." (LISPECTOR, 1997, p. 25). Conduzida por estes pensamentos, se alegra e continua curtindo seu ilusório momento de liberdade, o que a leva a pensar: "- eu era uma mulher casada e sou agora uma mulher". (LISPECTOR, 1997, p. 25). A partir daí, fica pensando como havia saído de casa naquele dia, como tudo havia acontecido tão rápido. Diante da impossibilidade de se manter longe do lar por mais tempo, a personagem volta para casa e se insere na rotina do lar que lhe apaga qualquer possibilidade de vontade própria.

Ao comentar sobre as personagens femininas de Clarice Lispector, Evando Nascimento (2012) identifica nessas figuras literárias a tentativa de elas se enveredarem por "passagens arriscadas [...], visando a transcender justamente a imanência pré-datada e predadora, dado culturalmente predeterminado". Nesse conto em análise, essa tentativa ocorre, justamente, através de uma revelação interior, ou seja, através de um momento de epifania. 
Esse momento epifânico do conto acontece quando a protagonista, percebendo o mundo à sua volta, muda sua forma de enxergar sua vida:

\begin{abstract}
Como foi que aquilo aconteceu? A princípio apenas um mal-estar e o calor. Depois qualquer coisa dentro dela começou a crescer. De repente, em movimentos pesados, minuciosos, puxou a roupa do corpo, estraçalhou-a, rasgou-a em longas tiras. O ar fechava-se em torno dela, apertava-a. Então um forte estrondo abalou a casa. Quase ao mesmo tempo, caí- ram grossos pingos d'água, mornos e espaçados.

Ficou imóvel no meio do quarto, ofegante. A chuva aumentava. [...] Agora era como um dilúvio (LISPECTOR, 1997, p. 26).
\end{abstract}

A personagem é influenciada a deixar sua casa por algo a ela exterior, ou seja, a chuva que chega e o calor que antecipa o temporal fazem esta mulher fugir de sua vida tediosa e socialmente moldada. Ao comentar as narrativas curtas de Clarice Lispector, Luiz Antônio Mousinho Magalhães faz a seguinte consideração sobre o modo como algumas personagens da autora passam por um momento de reconhecimento da realidade: "A percepção dos limites cotidianos e das possibilidades existentes para além da prisão familiar - tal percepção dada por contraste, é um dos maiores méritos dessas narrativas curtas de Clarice Lispector" (p. 138). Das duas citações apresentadas, podemos afirma que esse momento de percepção interior do conto em questão vem de um evento prosaico, o clima - calor e chuva -, que ganha um significado inusitado para a protagonista.

Este momento de epifania carrega um painel simbólico sobre o que acontece com esta mulher. Inicialmente, percebe-se que a protagonista, oprimida em sua domesticidade, associa o sufocamento social que sente com o calor do clima, com o ar imóvel e pesado, dando indícios de que não consegue perceber o que realmente a sufoca. Para se livrar desse sufocamento, ela arranca de si as roupas que a revestem, numa clara tentativa de libertar o seu corpo. Simbolicamente, despe-se do figurino socialmente construído para a mulher casada. Na sequência dos eventos, a água surge. Nesse processo de construção simbólica, a água vem como indício de nascimento, inicialmente, trazendo para a personagem uma nova possibilidade de vida, longe do que o lar representa. Imediatamente depois, a água surge com sentido duplo, morte e nascimento, representada na palavra dilúvio, utilizada aqui com o mesmo sentido 
que ela tem no livro de Gênesis. Isso demonstra que há uma morte do que a roupa antiga representava e o nascimento da novidade, vinda com a ação de pôr uma nova vestimenta: "vestiu-se, juntou todo o dinheiro que havia em casa e foi embora" (LISPECTOR, 1997, p. 26). Esse momento de epifania proporciona à protagonista a chance de experimentar a possibilidade de construir uma nova existência.

Com relação aos recursos utilizados nesse conto, chamamos atenção, inicialmente, para a construção da narrativa em media res, uma técnica que consiste em abrir uma história no meio da ação, e, através de flashback, suprir as informações iniciais. Assim, somos informados sobre a protagonista que se encontra na rua, debaixo de chuva e cansada. O modo como a narrativa se inicia é revelador porque caracteriza o estado de cansaço e esgotamento físico que a personagem vivencia. Este estado da protagonista no início do conto vai mostrar a luta que se instaura em seu interior, quando ela reluta em voltar para casa: "Esperou o momento em que ninguém passava para dizer com toda força: 'Você não voltará'. Apaziguou-se." (LISPECTOR, 1997, p. 24). Nesse contraste entre os espaços - rua e lar -, o conto vai focar no que o lar representa para a protagonista, mostrando que toda a simbologia de lugar acolhedor que este espaço possui é negada por aquilo que ele representa para a personagem. Assim, mesmo na chuva, cansada e solitária, ela dá sinais de que prefere o espaço da rua ao do lar.

Desse modo, o início da narrativa destaca a inquietação maior da personagem: voltar ou não voltar para casa. Diante da angústia dessa mulher, são retirados do texto indícios de ações da personagem e são destacados os pensamentos interiores dela, revelando toda uma gama de construção patriarcal que molda o feminino dentro do espaço do lar. O que é apresentado sobre o papel dessa personagem de Clarice Lispector como mulher se aproxima da caracterização da figura do feminino comumente exaltada, em diferentes períodos, como o ideal para o feminino. Este tipo de personagem se insere no que Simone de Beauvoir (1980) denomina de destino de mulher e no que Virginia Woolf caracteriza como "Anjo do lar" (1996): estas figuras femininas são mulheres identificadas como mães, genitoras, boas esposas, senhoras exemplares. Percebe-se que a criação literária procura dar às mulheres um 
caráter disciplinar, uma vez que sempre as põe inseridas em um contexto patriarcal, cuja visão androcêntrica faz com que essas personagens sejam submissas à vontade masculina e sigam sempre o ideal de mulher que esta mesma sociedade criou. Virginia Woolf, em um ensaio intitulado "Profissões para mulheres", descreve bem essa figura angelical ${ }^{2}$. Segundo Woolf, o "Anjo do lar"

[...] era intensamente compassiva. Era imensamente encantadora. Era profundamente abnegada. Ela dominava todas as difíceis artes da vida familiar. Sacrificava-se diariamente [...] A pureza era considerada sua maior beleza - o rubor de suas faces, sua graça maior. Naqueles dias - os últimos da Rainha Vitória - cada casa tinha o seu anjo. (WOOLF, 1996, p. 43-44).

Inserida num papel social que não lhe agrada, a protagonista de "A fuga" empreende, então, uma caminhada contrária ao que sua vida representa. Ela é casada com um homem de negócios, não trabalha fora de casa, tem até uma empregada para os afazeres domésticos, e, supostamente, passa o dia se entretendo com paliativos que a retiram da vida monótona, como o ato de ler. Ela se encaixaria no ideal patriarcal do padrão de uma mulher de classe média do Rio de Janeiro da época. Essas características sociais da personagem contribuem para tornar a sua vida uma existência tediosa. Isso é comprovado no momento em que ela descreve o passar dos dias diante da rotina da casa: "Vive atrás de uma janela, olhando pelos vidros a estação das chuvas cobrir a do sol, depois tornar o verão e ainda as chuvas de novo." (LISPECTOR, 1997, p. 25). Dessa descrição de sua vida, destacamos duas coisas: primeiramente, a sua inserção no espaço interno da casa, de onde ela vislumbra o que acontece fora dele; o segundo fator de destaque é seu estado contemplativo diante da vida que não para lá fora - uma estação tomando o lugar da outra.

O tédio que a vida representa está metaforizado na sua visão sobre o casamento, identificando nessa relação o grande problema de sua existência. Isso fica evidente quando ela, na rua e diante de um estranho, quer exteriorizar uma nova perspectiva existencial: "Meu filho, eu era uma mulher casada e sou agora uma mulher." (LISPECTOR, 1997, p. 25). Casada há mais de doze anos, o casamento tornou-se uma prisão, o motivo de ela buscar outro destino para si.

\footnotetext{
${ }^{2}$ Vale lembrar que termo usado por Virginia Woolf foi originalmente criado por Coventry Patmore, em um poema de 1885, intitulado "The Angel in the house" (cf. GILBERT; GUBAR, 1985, p. 956).
} 
Segundo a personagem, depois de ter casado, sua vida estacionou no tempo: "Há doze anos era casada e três horas de liberdade restituíam-na quase inteira a si mesma: - a primeira coisa a fazer era ver se as coisas ainda existiam." (LISPECTOR, 1997, p. 24). O casamento é uma condição tão opressora que os doze anos são ressignificados, ganhando uma conotação negativa.

Na simbologia do casamento, uma união de doze anos significaria bodas de seda ou ônix. No imaginário coletivo, a seda representa a maciez e o conforto do toque de uma superfície agradável. Quanto à pedra, de acordo com o Dicionário de símbolos, ônix pode sugerir proteção contra o mau-olhado (CHEVALIER; GHEERBRANT, 2002, p. 660). Tanto seda quanto ônix carregam uma simbologia positiva, para representar um período de casamento. Mas, na visão da protagonista, esse período não carrega positividade. Por isso, ele será transformado, inicialmente, em doze quilos de chumbo, sendo os quilos derretidos em dias e fundidos novamente para se materializarem na forma de âncora: "Os dias se derretem, fundem-se e formam um só bloco, uma âncora." (LISPECTOR, 1997, p. 25). Nessa representação do tempo de casada, a vivência como esposa é responsável por fazer a protagonista afundar como indivíduo de vontade, tornando-a cada dia mais presa ao papel doméstico criado para ela. A ideia de âncora levantada por ela mostra que não há como ela se entregar à imensidão do mar e ao navio que está prestes a partir, e que representariam a possibilidade de fuga completa que ela tanto almeja. Os doze quilos de chumbo também constituem uma metáfora para aprisionamento, revelando o sufocamento e cerceamento dessa personagem: "Doze anos pesam como quilos de chumbo e os dias se fecham em torno do corpo da gente e apertam cada vez mais." (LISPECTOR, 1997, p. 26).

Estes doze anos ainda serão transformados em doze séculos: "Porque esperou tanto tempo para esta renovação? Só hoje, depois de doze séculos." (LISPECTOR, 1997, p. 25). Esta hipérbole para o período de casada mostra que a passagem dos anos é lenta e dolorosa para esta mulher. Assim, entende-se que o grande cercado, o aprisionamento, e o cárcere se estendem por um tempo tão lento e angustiante que é impossível se livrar de tudo que a molda no papel de mulher casada: "Não posso ter raiva de mim, porque estou cansada. E mesmo 
tudo está acontecendo, eu não estou provocando nada. São doze anos." (LISPECTOR, 1997, p. 27).

A simbologia do número doze também serve para entender o processo pelo qual passa essa mulher do conto. Segundo o Dicionário de símbolos, "Doze é o número das divisões espaço-temporais". (CHEVALIER; GHEERBRANT, 2002, p. 348). Seguindo a definição apresentada para este número, a protagonista vivencia um momento crucial na sua vida de casada, que a leva a repensar o tempo e o espaço no qual ela está inserida. O dicionário ainda afirma que doze é, "em definitivo, e sempre, o número de uma realização, de um ciclo concluído" (CHEVALIER; GHEERBRANT, 2002, p. 349), o que nos faz afirmar que a protagonista entende como finalizado o seu tempo de casada, no instante que ela decide fugir do lar e do marido. Mas como doze "simboliza também o universo na sua complexidade interna", é possível dizer que a protagonista entende, no final do conto, que ela está cercada por um universo social complexo que a aprisiona ao casamento. A escolha desse número para representar o tempo de casada da protagonista ainda vai se ligar ao papel que o número doze tem no imaginário simbólico do cristianismo. Em diferentes partes da Bíblia, encontramos várias referências a ele que sedimentam o poder de Deus e suas construções: as 12 tribos do povo judeus, 12 discípulos, Jerusalém celeste com 12 portas, as 12 estrelas da coroa da mulher vestida com o sol, entre outras. Ainda, este número "representará a Igreja, a Igreja triunfante" (CHEVALIER; GHEERBRANT, 2002, p. 349). Isso reforça a ideia de que o tempo do casamento da protagonista é algo sólido e imutável para as construções do cristianismo, embora ela queira escapar dele.

Ainda em relação à constituição do casamento apresentada neste conto, o marido da personagem representa o opressor, ou seja, a mulher não consegue a vida que gostaria de ter porque tem que seguir as regras ditadas pelo homem. Toda a vida de negação desta mulher é simbolizada na atitude de ela não sentir fome ao lado do marido. Durante a sua peregrinação debaixo da chuva, a fome aparece: "Agora está com fome. Há doze anos não sente fome" (LISPECTOR, 1997, p. 26). Mas, ao retornar para casa, e encontrar o marido, a fome desaparece: "Toma um copo de leite quente porque não tem fome" (LISPECTOR, 1997, p. 27). Assim, a palavra fome deixa de representar o desejo 
físico e metaforiza todos os desejos tolhidos da personagem, pelos doze anos de casamento. É nas horas longe de casa, longe do marido, que a personagem comporta-se como realmente gostaria. Na rua, ela pode pensar, pode sorrir e pode decidir que rumo dar à sua vida.

Acrescentando outro ponto nessa abordagem sobre o casamento, a constituição do marido, oferecida pela visão da esposa, é significativa. Ele representa, assim como os anos, o que prende a mulher ao seu mundo doméstico e socialmente construído: "Os desejos são fantasmas que se diluem mal se acende a lâmpada do bom senso. Por que é que os maridos são o bom senso?" (LISPECTOR, 1997, p. 25). Dessa frase, dois pontos chamam a atenção do leitor: primeiro, entende-se que esta mulher possui veleidades e vontades, representadas pela metáfora dos fantasmas; mas, este é o segundo ponto, esses fantasmas são afugentados tão logo o bom senso aparece, metaforizando o papel do masculino na instituição casamento. Assim, diante do marido e do que ele representa, nada pode se feito por essa mulher para tornar reais seus desejos interiores. Esse marido ainda possui mais um agravante que dificulta qualquer exteriorização de vontades do feminino: ele é extremamente metódico, perfeccionista, sensato e ligado a padrões socialmente construídos. Toda essa caracterização do masculino tornaria o marido da protagonista ainda mais avesso a qualquer mudança de comportamento dela:

\footnotetext{
O seu [marido] é particularmente sólido, bom e nunca erra. Das pessoas que só usam uma marca de lápis e dizem de cor o que está escrito na sola dos sapatos. Você pode perguntar-Ihe sem receio qual o horário dos trens, o jornal de maior circulação e mesmo em que região do globo os macacos se reproduzem com maior rapidez. (LISPECTOR, 1997, p. 25).
}

Outro ponto importante para entender a situação de aprisionamento em que se encontra a personagem vem da escolha feita pela escritora para identificar o lugar de onde parte esta mulher em sua empreitada de fuga: "Ela tomara o ônibus da Tijuca e saltara na Glória. Já andara para além do Morro da Viúva." (LISPECTOR, 1997, p. 24). A identificação do ponto de partida na Tijuca revela que o espaço onde a personagem inicia sua caminhada é um lugar desconfortável, fétido e lodoso. Segundo o Dicionário infopédia da Língua Portuguesa com Acordo Ortográfico, vocábulo "tijuco(a)" é de origem tupi e 
significa líquido podre, lama. Carregando em si a ideia de atoleiro, entende-se que não só o espaço da casa é angustiante, mas também o bairro onde este ambiente doméstico se encontra é desconfortável. Isso fica ainda mais evidente, se levarmos em conta os outros dois espaços da cidade do Rio de Janeiro explicitados nesse trecho: Glória e Morro da Viúva. O primeiro constitui o ponto de descida do ônibus e simboliza o reconhecimento de um feito quase heroico dessa personagem que se distancia da lama. Já o segundo espaço, o Morro da Viúva, anuncia um suposto desejo maior da personagem de se ver livre da ligação com o marido.

Diante do exposto, devemos lembrar que, embora a fuga empreendida pela personagem ganhe forma na narrativa, os anos e a figura do marido fazem com que ela retorne ao socialmente construído para ela.

Numa tentativa de entender o que está acontecendo em sua vida, a personagem segue devaneando, imaginando como tinha surgido aquele desejo de liberdade e como poderia fazer para prolongá-lo, mas percebe que lhe falta coragem para tal empreitada, e na deficiência de sua coragem, ela volta para casa. Vejamos o texto: "Oh!, tudo isso é mentira [...] Volto para casa. Não posso ter raiva de mim [...]" (LISPECTOR, 1997, p. 27). A narrativa se fecha com a personagem envolvida nas mesmas relações de sempre, o que demonstra o seu estado de passividade letárgica. Assim, o conto nos mostra que o momento de epifania da protagonista não foi suficiente para ela empreender por completo seu plano de fuga. Presa a convenções e ciente de que não tem como sobreviver no seu contexto social, ela se reconhece cansada e entende o casamento como algo solidificado. Sua caminhada, nestas três horas de liberdade, não foi suficiente para chegar a um porto seguro para iniciar uma nova existência. Desse modo, é possível identificar a outra categoria joyceana nessa criação de Clarice Lispector: a paralisia.

Embora a narrativa mostre a personagem em uma fuga, caminhando pela cidade, durante uma chuva forte, devemos entender que essa ação não lhe oferece o que ela deseja completamente: fugir de tudo o que o lar representaria. Os passos que ela trilha são circulares, fazendo com que volte ao ponto inicial de sua rota de fuga: ao lar, ao bairro da Tijuca com sua simbologia de lamaçal. O que predomina na narrativa, como já antecipamos, são os pensamentos 
interiores da personagem. Assim, apenas em pensamento, ela se projeta em diferentes lugares, numa tentativa de construir um futuro que não se concretiza. A narrativa deixa claro que, sem sair do ponto de onde contempla o mar, a personagem visita mentalmente diferentes espaços da nova vida: "Entrará num restaurante"; "O quarto de hotel tem um ar estrangeiro"; "o navio parte às duas horas" (LISPECTOR, 1997, p. 26). Os dois primeiros lugares são apenas pontos de apoio - o restaurante e o quarto de hotel -; já o segundo, o navio, simboliza o total distanciamento do espaço maior de onde ela procura fugir: a cidade do Rio de Janeiro.

Apesar de toda a angústia que esta decisão possa lhe causar, a fugitiva volta atrás em seu plano de fuga. São dois os motivos mais fortes que fazem a personagem criada por Clarice Lispector desistir de seus planos. O primeiro deles é a fragilidade da personagem diante das correntes que o casamento possui. Os seus doze anos de casada estão tão presentes e solidificados em sua pessoa que não podem ser postos de lado. Esta mulher fugitiva tem um bloco de chumbo prendendo-a para sempre ao seu lar. O segundo motivo que a faz abortar o seu projeto de liberdade é o que as outras pessoas poderiam pensar dela e como sua ação teria consequência para o marido: "Bem que podia ir a um hotel. Isso é verdade. Mas os hotéis do Rio não são próprios para uma senhora desacompanhada, salvo os de primeira classe. E nestes pode encontrar algum conhecido do marido, o que certamente lhe prejudicará os negócios." (LISPECTOR, 1997, p. 26). Reconhecendo-se incapaz de dar os passos seguintes para sua liberdade, a personagem entrega-se ao peso do chumbo e decide voltar para o lar e para o seu papel social de esposa, de dona de casa.

Nos momentos finais do conto, temos uma frase que se mostra ambígua e que representa a fraqueza da protagonista diante do que a vida lhe oferece. Ao encontrar o marido em casa depois das horas de liberdade na rua, a personagem feminina pergunta se ele "Não recebeu seu recado avisando que só voltaria de noite?", ao que ele responde "Não" (LISPECTOR, 1997, p. 27). A fala da mulher deixa o leitor perceber que esta personagem tenta maquiar para o marido suas horas longe do lar, ao anunciar que tinha deixado a hora que voltaria para casa, no momento de sua saída. A sua fala ainda levanta a possibilidade de a narrativa apresentar uma afirmação para o leitor de que a fuga 
da mulher tinha um retorno preciso ao lar, uma vez que, sendo verdade que ela deixou tal recado ao sair, ela não pretendia demorar nem ir muito longe. Ou seja, se a afirmação dada ao marido, anunciando sua volta, for verdade, ela não planejava fugir de casa, mas apenas ensaiou uma fuga fictícia, para restituir-lhe um pouco de felicidade. E se a afirmação for falsa, ela tentava esconder do "bom senso", isto é, do marido, sua caminhada pela cidade a procura de um destino diferente do lar. Nos dois casos, fica evidente que as horas longe de casa não representam mudanças para esta mulher, fazendo com que sua caminha pelas ruas ganhe um sentido de inércia, de paralisia.

\section{O fim do caminho}

Instigada a sair de casa para dar vasão ao desejo interior de descobrir "se as coisas ainda existiam" (LISPECTOR, 1997, p. 24), esta mulher percebe que não é possível conquistar a sua liberdade, por isso ela volta à sua casa, recolhese ao quarto e deita-se em sua cama. Ela termina da mesma forma que sempre viveu, como uma prisioneira, cercada por grades socialmente construídas.

Neste conto, vemos que a personagem feminina encontra-se rodeada por grilhões que a impede de ter os seus projetos existenciais realizados. Por mais que ela pense, que pondere sobre sua existência, está fadada a um aborto pessoal.

Embora o narrador não nos dê uma visão detalhada da vida desta personagem, podemos inferir, através das pistas deixadas ao longo do texto, como tem sido a existência dela. Passa dias monótonos e angustiantes. Não há referência a instantes de felicidade ou alegria desde que ela se casou. A vida, com tudo que há de bom e excitante, chega até ela através de uma janela ou pelas páginas de um livro. A janela simboliza o desejo de viver o que há fora de sua casa, assim como simboliza tudo o que a prende dentro do lar. O livro oferece um conforto ficcional de uma possível existência que não a dela.

Assim, a função do momento de epifania é nula e apenas aponta para a total inaptidão dessa mulher de se livrar de tudo o que o seu casamento representa. Paralisada diante dos grilhões que a prendem à "cena diária": junto à janela e com o livro na mão, ela recolhe-se ao desconforto do lar e vê afastar- 
se dela qualquer chance de mudança: "Dentro do silêncio da noite, o navio se afasta cada vez mais" (LISPECTOR, 1997, p. 27). Metaforizada no navio, sua liberdade é vista como um ponto longínquo, que se distancia dela à medida que o tempo passa, dando-Ihe a certeza de que está presa ao chumbo do casamento e da forma social que o moldou.

\section{Referências:}

BEAUVOIR, Simone de. O segundo sexo. Rio de Janeiro: Nova Fronteira, 1980.

BROWN, Terence. Introduction. In: JOYCE, James. Dubliners. New York: Peguin, 2000. p. vii-xviii.

CHEVALIER, Jean; GHEERBRANT, Alain. Dicionário de símbolos: mitos, sonhos, costumes, gestos, formas, figuras, cores, número. Rio de Janeiro: José Olympio, 2002.

Dicionário infopédia da Língua Portuguesa com Acordo Ortográfico [em linha] (2003-2017). Porto: Porto Editora. Disponível em:

https://www.infopedia.pt/dicionarios/lingua-portuguesa/tijuco. Acesso em: 07 nov. 2017.

GILBERT, Sandra M.; GUBAR, Susan. The Norton anthology of literature by women: the tradition in English. New York; London: W. W. Norton \& Company, 1985.

JOYCE, James. Dubliners. New York: Penguin, 2000.

JOYCE, James. Dublinenses. Rio de Janeiro: Civilização Brasileira, 2006.

JOYCE, James. Stephen hero. New York: New Directions, 1963.

JOYCE, James. Stephen herói. São Paulo: Hedra, 2012.

LIMA, Luciano Rodrigues. Clarice Lispector comparada: narrativas de conscientização em Clarice Lispector, Virginia Woolf, Susan Glaspell, Katherine Mansfield e A. S. Byatt. Salvador: EDUFBA, 2008.

LISPECTOR, Clarice. A fuga. In: LISPECTOR, Clarice. O primeiro beijo e outros contos. São Paulo: Ática, 1997, p. 23-27.

MAGALHÃES, Luiz Antônio Mousinho. Uma escuridão em movimento: as relações familiares em Laços de família de Clarice Lispector. João Pessoa: Ideia; Ed. Universitária UFPB, 1997. 
NASCIMENTO, Evando. Clarice Lispector: uma literatura pensante. Rio de Janeiro, Civilização Brasileira, 2012.

PENNA, João Camillo. O nu de Clarice Lispector. ALEA, Rio de Janeiro, v. 12, n. 1, p. 69-96, jan./jun., 2010.

ROSAS, Marta. Sofisticada simplicidade. In: MANSFIELD, Katherine. Je ne parle pas français e outros contos. Rio de Janeiro: Revan, 1999. p. 7-11.

SCHOLES, Robert; WALZL, Florence L. The epiphanies of Joyce. PMLA, v. 82, n. 1, p. 152-154, mar. 1967. Disponível em: http://www.jstor.org/stable/461060. Acesso em: 17 nov. 2017.

WOOLF, Virginia. Profissões para mulheres. In: WOOLF, Virginia. Kew gardens: o status intelectual da mulher, um toque feminino na ficção, profissões para mulheres. São Paulo: Paz e Terra, 1996. p. 41-50. 